\title{
Recent Eurasian winter temperature change and its association with Arctic sea-ice loss
}

\author{
Hye-Jin Kim (i) \& Seok-Woo Son (i) \\ School of Earth and Environmental Sciences, Seoul National University, Gwanak-gu, Seoul, South Korea
}

\begin{abstract}
The surface air temperature in the northern mid-latitudes during winter showed a significant cooling trend from the late 1990s to the early 2010s, in spite of increasing greenhouse gas concentrations. This unexpected cooling, which was particularly strong across Eurasia, has been partly attributed to Arctic sea-ice loss. Here, the statistical relationship between Arctic sea-ice loss and surface air-temperature change during winter in Eurasia, which is often referred to as the warm Arctic-cold Eurasia pattern, is re-evaluated by using a break-point trend analysis and maximum covariance analysis. A significant time-lagged covariability is observed between the Arctic sea-ice concentration over the Barents-Kara seas and the Eurasian surface air temperature during winter, with the former leading the latter by approximately two months. More importantly, the timing of an abrupt decline in the autumn Arctic sea ice that occurred in the late 1990s is coincident with the beginning of the Eurasian winter cooling. This concurrent trend change is statistically significant and robustly found in both the break-point analysis and maximum covariance analysis. These results suggest that both the interannual variability and decadal trend change seen for the surface air temperature during Eurasian winters are likely influenced by regional sea-ice changes over the Barents-Kara seas.
\end{abstract}

\section{Keywords}

Warm Arctic-cold Eurasia; Eurasian winter cooling; Barents-Kara sea-ice loss

\section{Correspondence}

Seok-Woo Son, School of Earth and Environmental Sciences, Seoul National University, 1 Gwanak-ro, Gwanak-gu, Seoul, 08826, South Korea. E-mail: seokwooson@ snu.ac.kr

\begin{abstract}
Abbreviations
AO: Arctic Oscillation; BK: Barents-Kara seas; CC: correlation coefficient; DJF: December-February; EC: expansion coefficient; ERSST: extended reconstructed sea surface temperature data set; GISTEMP: Goddard's global surface temperature analysis data set; JJA: June-August; MCA: maximum covariance analysis; NASA: National Aeronautics and Space Administration (USA); NDJ: November-January; NH: Northern Hemisphere; OND: October-December; PDO: Pacific Decadal Oscillation; SAT: surface air temperature; SCF: squared covariance fraction; SIC: sea-ice concentration; SMMR: scanning multichannel microwave radiometer; SON: September-November; SSM/l: special sensor microwave/imager; SSMIS: special sensor microwave imager sounder; SST: sea-surface temperature; WACE: warm Arctic-cold Eurasia
\end{abstract}

\section{Introduction}

The fact that the global mean SAT stopped increasing from the late 1990s to the early 2010s is well documented, and is often referred to as the global warming hiatus (Kaufmann et al. 2011; Kosaka \& Xie 2013; Meehl et al. 2013; Meehl et al. 2014). This change was not spatially homogeneous but was mainly observed in the northern mid-latitudes (Li et al. 2015). This warming hiatus was dominated by rapid cooling over the North American and Eurasian continents in the boreal winter (Cohen et al. 2012a, b; Li et al. 2015).

Although a cooling trend in the hiatus period was observed both in North America and Eurasia, the underlying mechanisms are somewhat likely different between the two regions. North American cooling has been related to SST variability in the equatorial Pacific such as the PDO and El Niño-Southern Oscillation (Meehl et al. 2011; Kosaka \& Xie 2013; Meehl et al. 2013) along with the rapid decline in the Arctic SIC (Screen 2017). In the case of Eurasian cooling, the impact of SST variability is rather minor (Kosaka $\delta$ Xie 2013). This cooling has instead been explained by the Arctic warming and/or the associated SIC decrease (Honda et al. 2009; Petoukhov \& Semenov 2010; Kim et al. 2014; Mori et al. 2014; Peings \& Magnusdottir 2014; Barnes \& Screen 2015; Kug et al. 2015; Overland et al. 2015; Mori et al. 2019) and internal atmospheric variability (Li et al. 2015; McCusker et al. 2016; Sun et al. 2016; Ogawa et al. 2018). 
The link between the Arctic and the Eurasian SAT, the so-called WACE pattern (Mori et al. 2014), has been highlighted in many studies mainly based on interannual covariability. Mori et al. (2014) reported that the WACE pattern is the second leading mode of extratropical winter SAT variability in the Eastern Hemisphere, while the $\mathrm{AO}$ is the first leading mode. By performing cyclostationary empirical orthogonal function analysis, Kim \& Son (2016) showed that the WACE pattern, rather than the $\mathrm{AO}$, is the leading mode of extratropical SAT variability in the NH winter. Outten $\&$ Esau (2012) also showed that the primary mode of interannual covariability between Arctic SIC and Eurasian SAT anomalies has a WACE-like pattern.

Although the causal relationship between Arctic SIC and Eurasian SAT is not clear, previous studies have shown that Arctic SIC anomalies often lead to Eurasian SAT anomalies (Cohen et al. 2012a; Liu et al. 2012; Tang et al. 2013; Kim et al. 2014; Overland et al. 2015; Chen et al. 2016). For instance, the BK SIC decline since the late 1990s is maximum in autumn, not in winter (Walsh 2014), while the Eurasian cooling occurs only in winter (Cohen et al. 2012b). At an interannual time scale, Eurasian winter SAT anomalies are more strongly correlated with the BK SIC anomalies in the preceding autumn than those in the concurrent winter (Overland et al. 2015). These results imply that Arctic sea-ice loss could be a leading factor in Eurasian winter cooling at interannual to decadal time scales (Honda et al. 2009; Inoue et al. 2012; Kim et al. 2014; Kug et al. 2015; King et al. 2016; Zhang et al. 2018).

To update and extend these studies, the present study revisits the statistical relationship between the Arctic SIC and the Eurasian winter SAT. Although their covariability is well-documented, the optimal time lag between the SIC and SAT anomalies has not been quantified. No time lag or a seasonal lag (SAT lagging SIC) has been used in the literature without any justification. The methodologies employed in some of the aforementioned studies also need to be revised. The use of the detrended time series is particularly problematic because both the SIC and SAT exhibit a significant decadal trend change. Furthermore, the timing of the decadal trend change (e.g., 1990, 1998, 1999 or 2002) is set subjectively in most previous studies (Cohen et al. 2012b; Li et al. 2015; McCusker et al. 2016; Sun et al. 2016), and it is unclear whether these subjective choices are physically or statistically meaningful.

In this study, we first determine the year (or period) when the decadal trend change of Arctic SIC and Eurasian winter SAT begins. Specifically, the starting year of the Eurasian winter cooling is objectively identified by conducting a break-point analysis, and this result is compared with the timing of the abrupt decline in Arctic SIC. The interannual covariability of Arctic SIC and Eurasian SAT anomalies is also quantitatively evaluated using MCA. This method aims to better quantify the optimal time lag between Arctic SIC and Eurasian winter SAT variability without removing their linear trends. The possible impact of Arctic SIC change on Eurasian winter cooling is also briefly discussed by decomposing the SAT trend into a linearly congruent trend with the Arctic SIC loss and others.

\section{Data and methods}

\section{Data}

We use monthly mean SIC data obtained from the Nimbus-7 SMMR and the US Defense Program SSM/I-SSMIS Passive Microwave Data set, version 1 using the NASA Team sea-ice algorithm (https://nsidc. org/data/NSIDC-0051; Cavalieri et al. 1996). These data were originally generated from brightness temperature data in a polar stereographic projection with a $25-\mathrm{km}$ horizontal resolution but are interpolated into latitude and longitude grids with a $1^{\circ}$ resolution. Following previous studies, the Eurasian SAT is primarily related to the BK SIC. Here, the BK domain is set to $70-80^{\circ} \mathrm{N}$ and 30-70 ${ }^{\circ} \mathrm{E}$ (Kug et al. 2015).

The monthly mean SAT is obtained from NASA's GISTEMP, which combines the SAT obtained from the Global Historical Climatology Network data set version 3 and the SST obtained from ERSST version $3 b$ (Hansen et al. 2010) for the period 1979-2014. The temperature anomalies, relative to the reference period of 1951-1980, are available in a $2^{\circ}$ resolution. All the results are shown for the $\mathrm{NH}$ extratropics, north of $20^{\circ} \mathrm{N}$. The regional domains are set to $35-60^{\circ} \mathrm{N}$ and $50-130^{\circ} \mathrm{E}$ for Eurasia and $25-50^{\circ} \mathrm{N}$ and $75-120^{\circ} \mathrm{W}$ for North America.

In this study, the analysis period is set to 1979-2014. The break-point analysis (see below) is sensitive to the analysis period. This is not a specific problem of the break-point analysis; rather, it is a common linear regression issue. To reduce unnecessary noise, it is important to properly set the starting and ending years. In this study, the starting year is set to 1979 to match the sea-ice data. However, in consideration of the anomalously warm Eurasian SATs in the winters of 2014/15 and 2015/16, the ending year is set to 2014 (e.g., Blunden \& Arndt 2016, 2017; Xu et al. 2018). As this study aims to identify the Eurasian SAT trend change that began when the Arctic sea ice abruptly started to decrease, the most recent few years are excluded from the analysis. 


\section{Break-point analysis}

One of the main goals of the present study is to detect the change in a linear trend. Many approaches have been proposed to incorporate trend change(s) in linear regression models. We adopt the regression model that allows only one time-break point in the linear trend (Perron $\delta$ Yabu 2009; Estrada et al. 2013).

$$
\begin{aligned}
& y(t)=\alpha t+\beta d t+y_{\mathrm{O}}+n(t) \\
& d t=t-t_{\mathrm{B}} t>t_{\mathrm{B}} \\
& d t=0 t \leq t_{\mathrm{B}}
\end{aligned}
$$

Here, $y$ and $t$ denote the variable of interest and time in years, respectively. The two coefficients, $\alpha$ and $\beta$, determine the first trend before the break point $\left(t_{\mathrm{B}}\right)$ and the second trend after the break point, respectively. The linear trend from $t=1$ to $t=t_{\mathrm{B}}$ is set by $\alpha$, whereas the later trend from $t=t_{\mathrm{B}}+1$ to $t=t_{\text {max }}$ is set by $\alpha+\beta$. Since the analysed time period is 35 years, from 1979 to 2013, the value of $t_{\max }$ is 35 . The last two terms in the equation, $y_{0}$ and $n(t)$, are the $y$ intercept and the residual component, respectively. Note that Eqn. 1 differs from a simple linear regression because of $d t$. This term, which is absent in a simple linear regression model, defines the break point in the linear trend.

The best estimate of the break year, $t_{\mathrm{B}}$, is determined by using the least-squared error. With the initial guess of the break year $t_{\mathrm{B}}$ ranging from 1 to 35 , the value that satisfies the minimum squared error between the observed time series and the two regressions fits from $t=1$ to $t=t_{\mathrm{B}}$ and from $t=t_{\mathrm{B}}+\mathrm{l}$ to $t=t_{\max }$ is considered to be the best estimation. The uncertainty of the trend change is then evaluated by examining the confidence interval proposed by Chang \& Perron (2016). Only when the $95 \%$ confidence interval does not cross either the start (1979) or the end years (2013) of the analysed period, is the detected break point believed to be physically or statistically meaningful. Otherwise, the time series is considered to have no trend change.

Before the break-point analysis is conducted, the stationarity of the time series that is required for the linear regression analysis (Fuller 1976) must be evaluated with the unit root test incorporating the break point (Kim $\&$ Perron 2009). Although not shown, it was found that both the SAT and SIC time series, averaged over the analysis domains, are stationary at a $1 \%$ significance level. This implies that the area-averaged SAT and SIC time series are suitable for the regression analysis with a break point.

\section{MCA}

To better understand the interannual covariability between the Arctic SIC and mid-latitude SAT, we also performed an MCA. The MCA is based on the singular value decomposition of the covariance matrix of the two variables (Bretherton et al. 1992; Wallace et al. 1992). Only the Eastern Hemisphere is considered for both the Arctic SIC $\left(0-180^{\circ} \mathrm{E}\right.$ and $\left.60-90^{\circ} \mathrm{N}\right)$ and extratropical SAT anomalies $\left(0-180^{\circ} \mathrm{E}\right.$ and $\left.30-90^{\circ} \mathrm{N}\right)$, as stated by Mori et al. (2014). To find the optimal time lag, SON, OND, NDJ and DJF SIC anomalies are tested against DJF SAT anomalies.

Although detrended data are often used in the MCA, raw data are used in this study. Detrended data would be more useful than the raw data for isolating interannual covariability only if the variables of interest have linear trends. As shown later in this paper, both the Arctic SIC and Eurasian SAT have nonlinear trends with a significant trend change in the late 1990s. This makes the use of detrended data questionable. The use of raw data also allows us to investigate whether the leading EC time series (see below) can reproduce the observed break point.

The MCA is specifically conducted as follows. The $\operatorname{SAT}(x, t)$ at a grid point $x$ and time $t$ and the $\operatorname{SIC}(x, t+\tau)$ at time $t+\tau$ are expanded in the MCA.

$$
\begin{array}{r}
S A T^{*}(x, t)=\sum_{n}^{N} A_{n}(x) a_{n}(t) \\
S I C *(x, t+\tau)=\sum_{n}^{N} B_{n}(x) b_{n}(t+\tau),
\end{array}
$$

where $S A T^{*}$ and $S I C^{*}$ denote SAT and SIC anomalies, respectively. The time series $a_{n}(t)$ and $b_{n}(t+\tau)$ are the $n$th EC time series obtained from the projection of the $n$th singular vectors $A_{n}(x)$ and $B_{n}(x)$, obtained by the singular value decomposition of the covariance matrix, onto their original data. Here, the singular vectors are normalized and nondimensionalized, but the ECs have the same dimension as the raw data. Because we are mainly interested in SIC-induced SAT changes, $\tau$ is set to zero to negative values (e.g., $\tau=-1$ for NDJ SIC vs. DJF SAT anomalies). The homogeneous SIC map and the heterogeneous SAT map are constructed by projecting $\operatorname{SIC}^{*}(x, t+\tau)$ and $S A T^{*}(x, t)$, respectively, onto $b_{n}(t+\tau)$ (Bretherton et al. 1992; Czaja $\delta$ Frankignoul 2002). Before the projection, $b_{n}(t+\tau)$ is scaled to make the homogeneous and heterogeneous maps have the same dimensions as the input data.

There is no formal procedure to evaluate the statistical significance of an MCA. As such, an empirical significance test, based on the bootstrap method, is carried 
out, as stated by Czaja \& Frankignoul (2002). The MCA is repeated with the original SIC data and the randomly resampled DJF SAT data. This resampling is conducted 100 times. The statistical significance is then evaluated by considering two metrics: the SCF, which is a ratio of the squared covariance of a first leading mode against the squared covariance of all others, and the CC between the leading EC time series of the SAT and SIC data sets. The significance level is defined by the percentage of resamples with an SCF or CC value equal to or greater than the value being tested.

\section{Decomposition of a linear trend}

The SAT anomalies, after the break point, are further decomposed into linearly congruent components with the SIC anomalies averaged over the BK $\left(S I C^{*}{ }_{\mathrm{BK}}\right)$ and residuals (Thompson et al. 2000). When the $S I C^{*}{ }_{\mathrm{BK}}$ time series is represented by the linear trend $(\alpha)$ and the residual $\epsilon_{1}(t)$,

$$
S I C *_{\mathrm{BK}}(t)=\alpha t+\epsilon_{1}(t)
$$

the $S A T^{*}$ time series can be regressed against $S I C^{*}{ }_{{ }_{B K}^{\prime}}$ as below:

$S A T *(x, t)=\beta(x) S I C{ }^{*}{ }_{\text {ВК }}(t)+\epsilon_{2}(x, t)=\alpha \beta(x) t+\epsilon_{3}(x, t)$,

where $\beta(x)$ is the regression coefficient of $S A T^{*}$ onto $S I C^{*}{ }_{{ }_{\mathrm{BK}}}$ and $\epsilon_{2}(x, t)$ is the residual in Eqn. 7. The coefficient $\alpha \beta(x)$ corresponds to the linear trend of $S A T^{*}$ that is congruent with the $S I C^{*}{ }_{\mathrm{BK}}$ trend. The residual trend, that is, the trend of $\varepsilon_{3}$, is considered to be independent of the $S I C^{*}{ }_{\text {BK }}$ trend. The linearly congruent trend is statistically significant only when both $\alpha$ and $\beta$ are statistically significant.

\section{Results}

Figure la-c presents the SAT time series and their linear trends in the NH extratropics, Eurasia and North America for summer JJA and winter DJF. Not surprisingly, the NH extratropical SAT has steadily increased from 1979 to 2014 in both seasons. However, the regional SAT trends have markedly different characteristics between seasons. In JJA, both the Eurasian and North American SATs show steady warming trends, with relatively weak interannual variabilities (red lines in Fig. 1b, c). In contrast, the DJF SATs show abrupt trend changes in the late 1990s with large variabilities (blue lines in Fig. 1b, c).

The break-point analysis revealed that the Eurasian and North American DJF SAT trends significantly changed in the late 1990s (Fig. 1b, c). The break point was particularly prominent in 1998. Note that although the detected year, 1998, has been empirically used in the literature (e.g., Kaufmann et al. 201 1; Li et al. 2015), it is objectively identified as a break-point year in this study. Notably, the detected year is somewhat sensitive to the choice of the analysis domain. With varying domain size, the break-point changes slightly but is still observed in the late 1990s (not shown). Importantly, as Fig. 1b, c show, the break point is statistically significant as the confidence interval does not cross the start and end years of the analysed period. Although a weak hint of the trend change is observed in the NH-extratropical SAT (Fig. la), this change is not significant. Likewise, the JJA SAT does not show any hint of the trend change.

Notably, the sign of both the Eurasian and North American SAT trends switched at the same time (e.g., year 1998 in Fig. 1b, c) with the different confidence intervals. This result raises at least two possibilities: (1) there was a $\mathrm{NH}$ circulation change that coherently affected both the Eurasian and North American SATs; or (2) two different physical processes, which independently affected the Eurasian and North American SATs, occurred by chance in the late 1990s.

This issue is briefly addressed by examining the spatial structure of the DJF SAT trends before and after 1998 (Fig. 1d, e). Before 1998, significant warming occurred in central to south-east Eurasia and the east coast of North America. A weak warming trend is also evident in northern Europe. In contrast, weak and insignificant cooling occurred at high latitudes, north of $60^{\circ} \mathrm{N}$. These trends, that is, the strong mid-latitude warming and weak Arctic cooling, basically flipped after 1998 (compare Fig. 1d, e). The Eurasian and North American warming trends were replaced by statistically significant cooling trends. Likewise, the Arctic warming became particularly strong over the Greenland and Barents seas.

Figure le further shows that the SAT trends over the North Pacific are statistically significant in the latter period. These trend patterns resemble the negative phase of the PDO (Bond et al. 2003) and are connected to the North American cooling trend through a wave-like trend pattern. These results may suggest that the DJF SAT-trend change in 1998 was likely associated with not only rapid warming in the Arctic but also a phase change in the PDO. The role of the PDO has been extensively discussed in the literature, and it is now well-accepted that North American SAT trend changes are influenced by PDO phase changes (Meehl et al. 2011; Kosaka \& Xie 2013; Meehl et al. 2013). However, the PDO cannot directly change the Eurasian SAT trend, as Eurasia is located upstream of the PDO region (Kosaka \& Xie 2013). Instead, Eurasian cooling is more closely associated with Arctic warming and related 

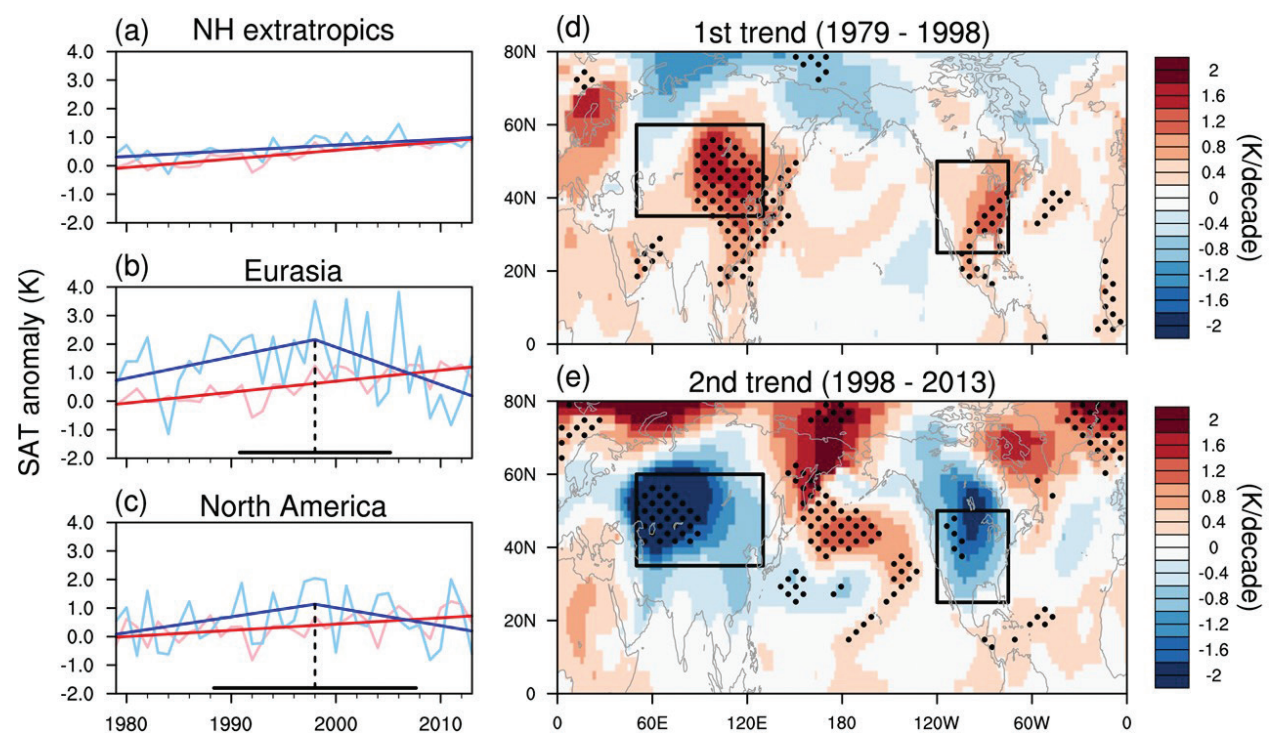

Fig. 1 Area-mean SAT and its linear trend in DJF (blue) and JJA (red): (a) the Northern Hemisphere extratropics, (b) Eurasia and (c) North America. Dashed lines represent an extended trend in the absence of a break point, and the black solid lines running parallel to the $x$ axis denote the $95 \%$ confidence interval of the estimated break point indicated by the black dashed lines. The right column shows the DJF SAT trend (d) before and (e) after 1998 . The values that are statistically significant at the $95 \%$ confidence level are dotted. Two boxes denote the Eurasian and North American domains.

atmospheric circulation changes (Honda et al. 2009; Petoukhov \& Semenov 2010; Mori et al. 2014; Peings \& Magnusdottir 2014; Barnes \& Screen 2015; Overland et al. 2015; Nakamura et al. 2016; Mori et al. 2019).

Did Arctic sea-ice loss start at the same time (or period) as Eurasian winter cooling? To address the SIC-SAT trend relationship, a break-point analysis was also performed with the BK SIC time series (Fig. 2). Notably, the BK SICs in autumn and winter abruptly decreased in approximately 1998 (Fig. 2a-d), coincident with the timing of the Eurasian winter cooling (compare Fig. $1 \mathrm{~b}$ and Fig. 2a-d). Unless they happened by chance, these results may suggest that the recent Eurasian cooling was partly associated with the BK sea-ice loss.

Figure 2e-h illustrates the spatial pattern of the Arctic SIC trend since 1998. In autumn (SON), the SIC shows a significant negative trend over broad regions from the BK to Chukchi seas (Fig. 2e). This negative trend is maintained in large areas of the Arctic ocean until the early winter (Fig. 2f, g) but is mainly restricted to the BK in DJF (Fig. 2h). This result indicates that BK SIC loss is a robust heat source for the atmosphere from autumn to winter. However, it is difficult to determine whether the autumn SIC decrease (and the accumulated heat release from the ocean to the atmosphere until winter) is more important than the concurrent winter SIC change.

To identify the optimal time lag (or the absence of the time lag), the relationship between the Arctic SIC and
Eurasian winter SAT anomalies is further quantified by MCA. The optimal time lag is determined with a maximum and statistically significant SCF. Note that although CC can be also used to define the lag, it does not allow a direct comparison among MCAs as each CC is computed by using different EC time series. Table 1 summarizes the information explained by the leading mode obtained from the MCA. The SCF of the leading modes exceeds $70 \%$ and the CC is greater than 0.7 for all time lags. More specifically, the first leading mode accounts for approximately $50 \%$ of the SIC variance and approximately $25 \%$ of the SAT variance. This indicates that the MCA results are robust regardless of the SIC reference season. However, not all results are statistically significant. The first mode of DJF SAT against DJF SIC shows a $23 \%$ significance level, which is much greater than any others (see the last column of Table 1). This result suggests that the mid-latitude SAT anomalies lag behind the Arctic SIC anomalies by at least one month.

Based on the maximum SCF and the MCA significance, the optimal covariability is found between the OND SIC and DJF SAT anomalies. The statistically significant CC in ECs in OND SIC and DJF SAT also implies that this mode well represents the association of winter SAT change with the autumn SIC change. Figure 3c, d illustrates the spatial and temporal structures of the leading mode of the OND SIC and DJF SAT anomalies, clearly showing the WACE-like pattern. More importantly, the resulting EC 

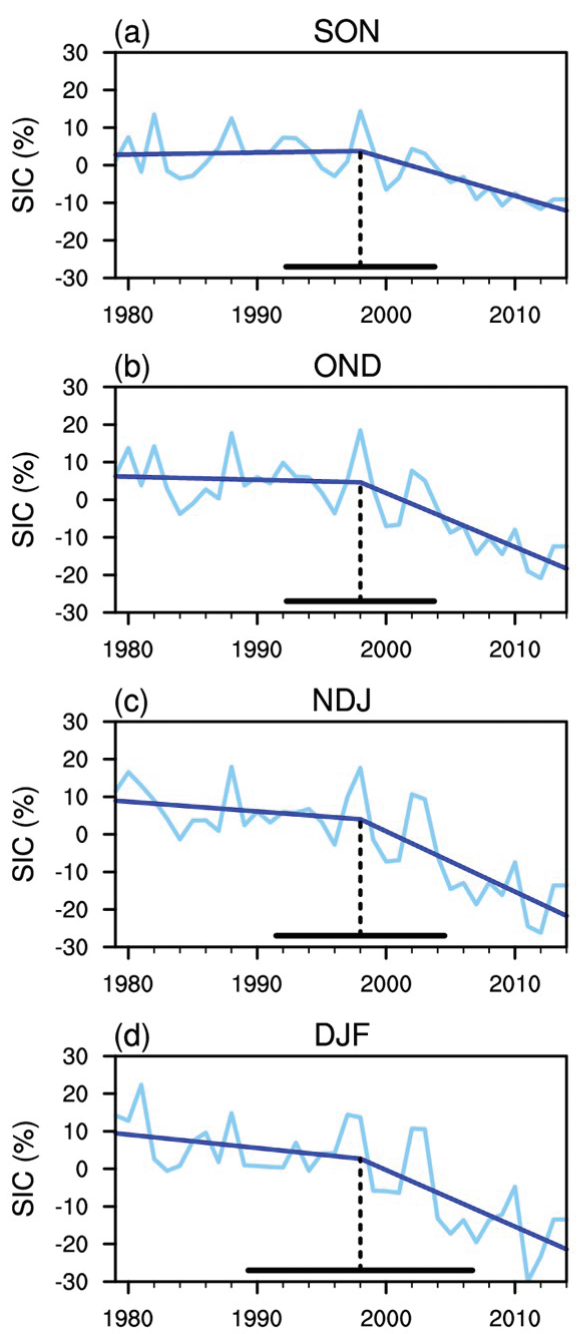

(e) SON trend (1998-2013)
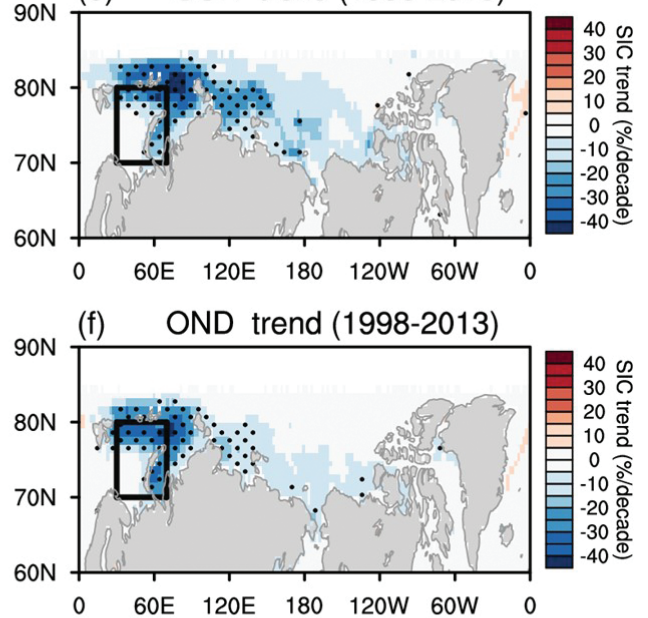

(g) NDJ trend (1998-2013)
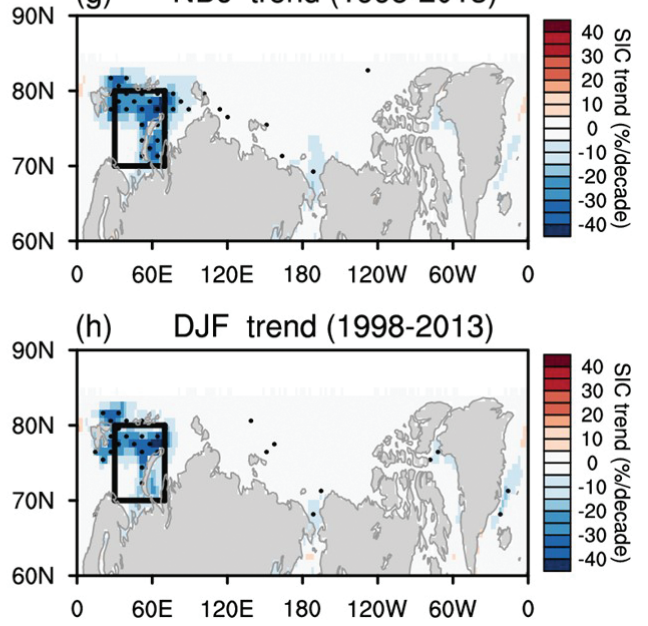

Fig. 2 (a) SON, (b) OND, (c) NDJ and (d) DJF SIC and their linear trends over the BK. The overall format is identical to that noted in Fig. 1a. Right panels show the linear trend in SIC in each season since 1998. The values that are statistically significant at the $95 \%$ confidence level are dotted. The boxes in the right column denote the domain of the BK.

time series (Fig. 3a, b) are closely related to the BK SIC (Fig. 2b) and Eurasian SAT time series (Fig. 1b). Their CCs are 0.94 for the SIC time series and 0.92 for the SAT time series. Both the interannual variability and the decadal trend change are well-captured by the leading EC time series. Note that although the break point of the SAT EC time series appears in 2001, it is not significantly different from the observed break point in 1998, as the confidence interval overlaps. Essentially, the same result is also found when monthly data, instead of three-month-averaged data, are used (not shown).

Here, we emphasize that the MCA results have at least two novel characteristics. (1) Because the SAT and SIC data in the Eastern Hemisphere, rather than those in a specified domain (e.g., Fig. 1), are used, the detected
Table 1 SCF, CC, percent variances of SIC and SAT and their significant levels explained by the first leading mode derived from the MCA for SON to DJF SICS and DJF SAT.

\begin{tabular}{lccccc}
\hline & SCF & CC & SIC & SAT & Sig. level \\
\hline SON SIC vs. DJF SAT & 83.07 & 0.74 & 48.14 & 25.59 & 3 \\
OND SIC vs. DJF SAT & 86.80 & 0.72 & 53.02 & 26.93 & 1 \\
NDJ SIC vs. DJF SAT & 78.63 & 0.74 & 54.19 & 23.29 & 10 \\
DJF SIC vs. DJF SAT & 72.36 & 0.85 & 54.21 & 20.47 & 23 \\
\hline
\end{tabular}

break points in Fig. 3, b are free from the influence of the analysis domain choice and prove the presence of the WACE-like trend change in the late 1990s. (2) The optimal time lag between the SIC and SAT anomalies is identified to be approximately two months based on 

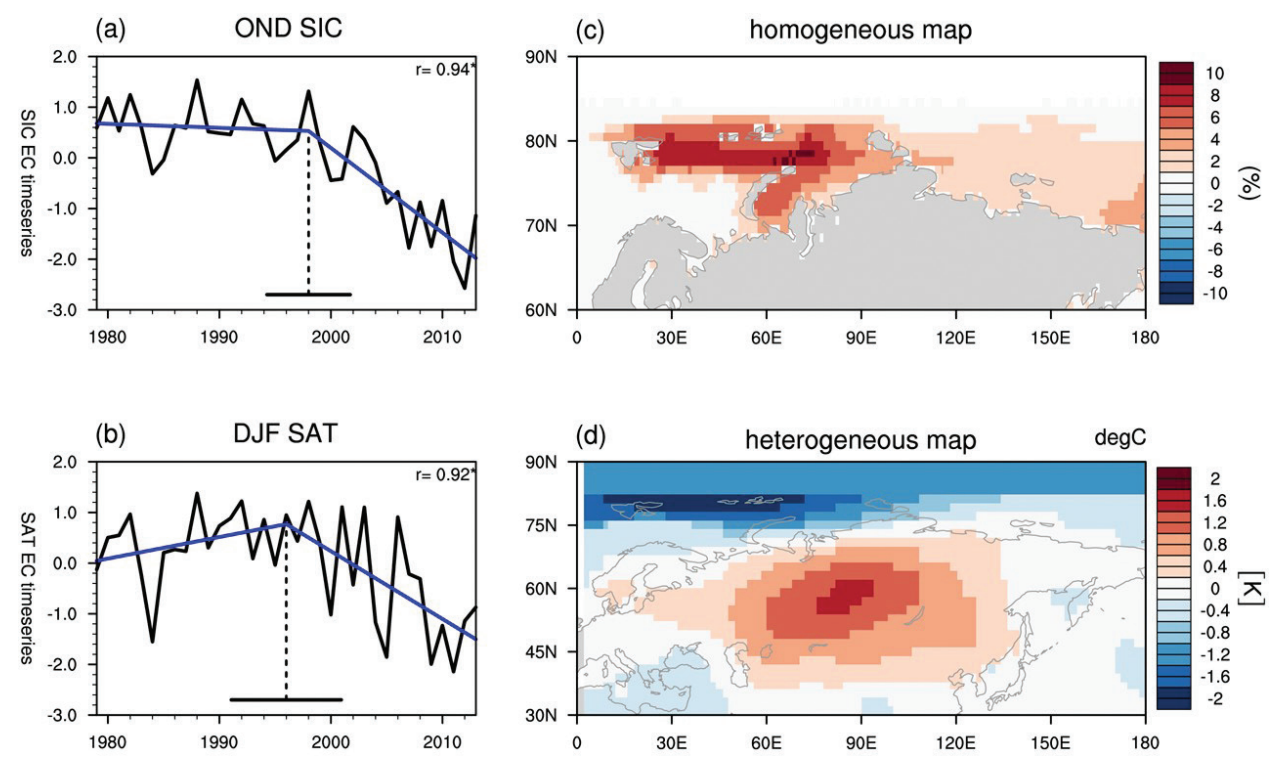

Fig. 3 (left) EC time series of the leading mode of the MCA and their trends of (a) the OND SIC and (b) DJF SAT. The overall format is identical to that of Fig. 1a. The numbers in the top right corners of (a) and (b) denote the correlation coefficients with the BK SIC time series (Fig. 2b) or the Eurasian SAT time series (Fig. 1b). The right column shows the (c) homogeneous (OND SIC projection onto the leading EC time series of OND SIC) and (d) heterogeneous (DJF SAT projection onto the leading EC time series of OND SIC) maps for the period: 1979-2013. Note that the latitudinal domain of (c) is different from that of (d).

interannual to decadal time scales. Although this result does not guarantee causality, it suggests that Eurasian SAT anomalies and their trends are likely influenced by Arctic sea ice and related large-scale atmospheric circulations.

Although not shown, the second mode is also examined. The EC time series of SIC in this mode is not strongly correlated with the BK SIC time series $(r=0.44$ in SON, $r=0.18$ in OND, $r=0.00$ in NDJ and $r=0.09$ in DJF). This indicates that the second mode does not represent BK SIC variability. Instead, the second mode is closely related to the AO index. The correlations between the second EC time series of the SAT and the AO index are 0.78 in OND, 0.82 in NDJ and 0.82 in DJF. These results complement the results given by Kim \& Son (2016), who identified WACE as the first leading mode of the $\mathrm{NH}$ winter SAT variability, while the second leading mode is AO-related.

The possible impact of Arctic sea-ice loss on the SAT trend is further quantified by decomposing the SAT trend from 1998 to 2013 into a trend that is linearly congruent with the OND sea-ice loss and the leftover (see the subsection on Decomposition of a linear trend in the Data and Methods section). The DJF SAT trend, which is linearly congruent with the OND BK SIC decrease, is presented in Fig. 4b. This trend resembles the DJF SAT trend very well (Fig. 4a), a result that again suggests that the Eurasian winter cooling since 1998 has at least partly been associated with the loss of autumn SIC over the BK.
It can be noted from Fig. $4 \mathrm{~b}$ that the SAT cooling over North America is partly related to the BK sea-ice loss. However, this cooling is unlikely to be directly associated with BK sea-ice loss. As discussed by Screen (2017), North American SAT is more sensitive to sea-ice variability in the East Siberian-Laptev seas and Greenland Sea. Because Arctic sea-ice loss is not limited to the BK but is observed to varying degrees in most Arctic Oceans, the North American cooling depicted in Fig. 4b is likely associated with the overall Arctic sea-ice loss.

\section{Discussion}

This study objectively identifies the optimal time lag between the Arctic SIC and Eurasian winter SAT variability. The decadal trend changes of Arctic SIC and Eurasian winter SAT are also quantitatively examined. The Eurasian winter SAT anomalies have maximum covariability with the autumn BK SIC anomalies with a time lag of approximately two months. More importantly, the linear trends of both the Eurasian winter SAT and the autumn BK SIC sharply changed in the late 1990s, indicating that the BK sea ice likely affected not only the interannual variability but also the decadal trend change of the Eurasian winter SAT.

The physical mechanism(s) behind this relationship is not addressed in this study. In the literature, the WACE pattern has been explained by two possible pathways: the tropospheric pathway and/or the stratospheric pathway. The tropospheric pathway suggests that Arctic 
(a) DJF SAT trend

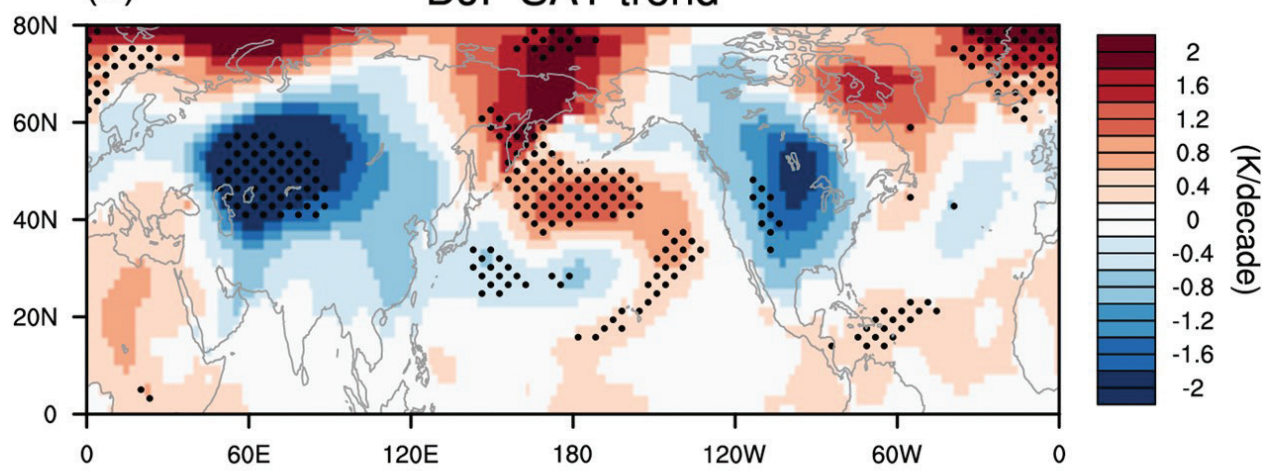

(b) linearly congruent with OND SIC

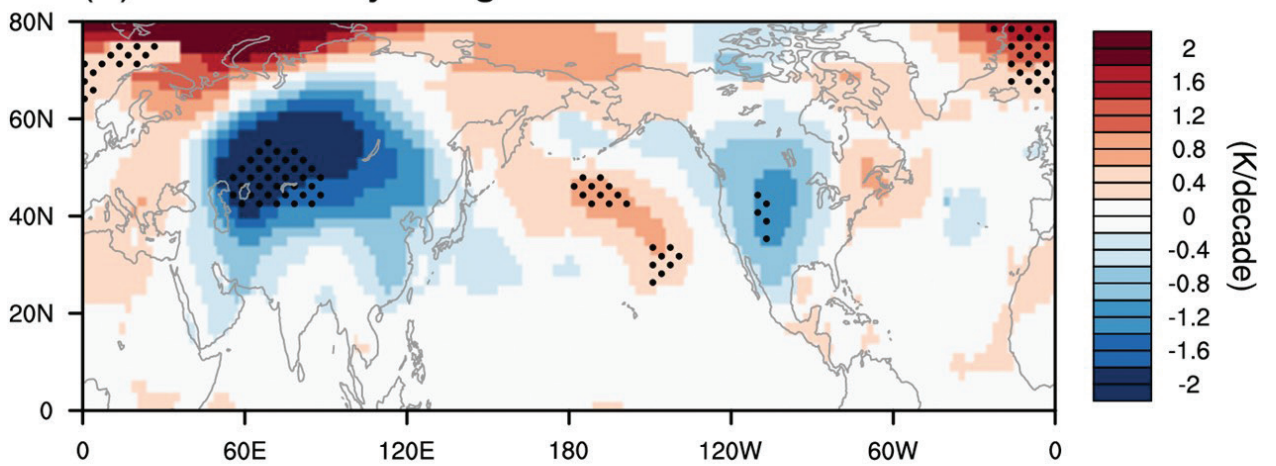

(c) residual component

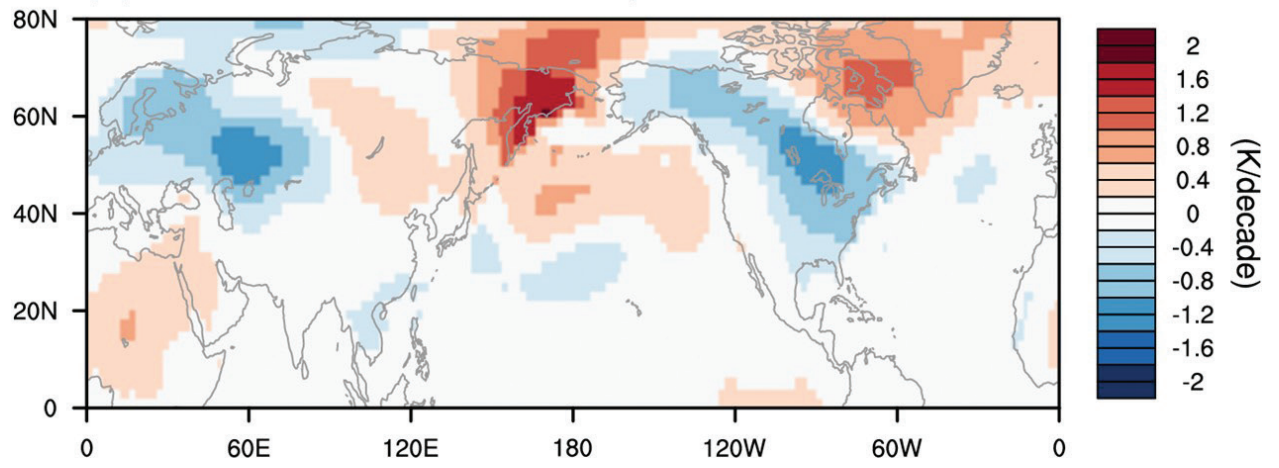

Fig. 4 (a) Linear trend in the DJF SAT, (b) the trend that is linearly congruent with the OND SIC trend over the BK and (c) the residual component for the period: 1998-2013. The values that are statistically significant at the 95\% confidence level are dotted.

sea-ice loss and the associated warming in the lower troposphere directly change atmospheric circulations, thus influencing the Eurasian winter SAT. Among others, Zhang et al. (2008) argued that the atmospheric circulation change over the Arctic could result in cold air advection from the Arctic to Eurasia. Honda et al. (2009) proposed that the BK sea-ice loss and the resulting lower-tropospheric heating may excite the Rossby waves that cause the WACE-like SAT anomaly pattern. In terms of transient eddy activities, Francis \& Vavrus (2012) further suggested that the recent Arctic warming may allow an enhanced meandering of the westerly jet, inducing more frequent cold air outbreaks in the mid-latitudes. Although these processes can explain the sub-seasonal relationship between the Arctic sea ice and Eurasian SAT variability, they cannot explain the two-month delayed response of the Eurasian winter SAT to the Arctic sea-ice changes. 
The lead-lag relationship can instead be explained by the stratospheric pathway. The key idea of this pathway is that the heat released by Arctic sea-ice loss can generate vertically propagating waves that weaken the stratospheric polar vortex. The weakened polar vortex can then affect the troposphere in a manner similar to the tropospheric circulation change in response to stratospheric sudden warming (Jaiser et al. 2013; Cohen et al. 2014; Kim et al. 2014; García-Serrano et al. 2015; Sun et al. 2015; Nakamura et al. 2016; Wu \& Smith 2016; Zhang et al. 2018). In fact, Nakamura et al. (2016) and Zhang et al. (2018) showed that the Eurasian winter SAT response to Arctic sea-ice anomalies disappeared when the model stratosphere was artificially dampened.

However, the stratospheric pathway does not hold for all climate models. A model that fully resolves the stratosphere, may fail to reproduce the WACE-like SAT response to Arctic sea-ice loss (Li et al. 2015). In such models, the WACE-like climate variability is not well reproduced (McCusker et al. 2016; Sun et al. 2016), making the stratospheric pathway questionable. Recent modelling studies have further argued that recent Eurasian winter cooling has simply been caused by natural variability (McCusker et al. 2016; Sun et al. 2016; Ogawa et al. 2018).

To reconcile the discrepancy among the model simulations, recent studies have attempted to directly compare climate model simulations by scaling the amplitudes of responses. By comparing six coupled models, Screen et al. (2018) concluded that the Siberian high is enhanced in response to the Arctic sea-ice loss, as indicated by observations. Mori et al. (2019) further showed that most climate models underestimate the WACE-like SAT response to Arctic sea-ice loss. By correcting this underestimation in the seven atmospheric general circulation models, they found that approximately $44 \%$ of the Eurasian winter cooling was likely caused by the BK sea-ice loss.

The multi-model analyse is one way to effectively reduce model uncertainty with the assumption that not all the models are wrong. However, model experiments with different forcings do not allow reliable comparisons. The use of organized multi-model experiments with the same model configuration would be helpful to better understand WACE-like NH winter climate change and variability and identify the dynamics underlying both. The Polar Amplification Model Intercomparison Project, a coordinated climate modelling experiment targeting the Arctic-to-mid-latitude teleconnection, is one such effort. Once these model outputs are available, the seasonal delay and trend relationships between the Arctic SIC and Eurasian SAT, as identified in the present study, can be more objectively explored.

\section{Acknowledgements}

We thank Prof. K.-Y. Kim for his helpful discussion.

\section{Disclosure statement}

The authors declare no conflict of interest.

\section{Funding}

This research was supported by the Korea Meteorological Administration Research and Development Program under grant KMI2018-01011.

\section{References}

Barnes E.A. \& Screen J.A. 2015. The impact of Arctic warming on the midlatitude jet-stream: can it? Has it? Will it? Wiley Interdisciplinary Reviews: Climate Change 6, 277-286, doi: 10.1002/wcc. 337.

Blunden J. \& Arndt D.S. (eds.) 2016. State of the climate in 2015. Bulletin of the American Meteorological Society 97(8), Supplement, doi: 10.1175/2016BAMSStateoftheClimate.1. Boston, MA: American Meteorological Society.

Blunden J. \& Arndt D.S. (eds.) 2017. State of the climate in 2016. Bulletin of the American Meteorological Society 98(8), Supplement, doi: 10.1175/2017BAMS State of the Climate.1. Boston, MA: American Meteorological Society.

Bond N.A., Overland J.E., Spillane M. \& Stabeno P. 2003. Recent shift in the state of the North Pacific. Geophysical Research Letters 30, article no. 2183, doi: 10.1029/2003GL018597.

Bretherton C.S., Smith C. \& Wallace J.M. 1992. An intercomparison of methods for finding coupled patterns in climate data. Journal of Climate 5, 541-560, doi: 10.1175/1520-0442(1992)005<0541:AIOMFF>2.0.CO;2.

Cavalieri D., Parkinson C., Gloersen P. \& Zwally H.J. 1996. Sea ice concentrations from Nimbus-7 SMMR and DMSP SSM/I passive microwave data. Boulder, CO: National Snow and Ice Data Center. doi: 10.5067/8GQ8LZQVL0VL. Accessed on the internet at http://nsidc.org/data/nsidc-0051.html. Colorado USA on, 15 May 2017.

Chang S.Y. \& Perron P. 2016 . A comparison of alternative methods to construct confidence intervals for the estimate of a break date in linear regression models. Econometric Reviews 37, 577-601, doi: 10.1080/07474938.2015.1122142.

Chen H.W., Alley R.B. \& Zhang F. 2016. Interannual Arctic sea ice variability and associated winter weather patterns: a regional perspective for 1979-2014. Journal of Geophysical Research-Atmospheres 121, 14433-14455, doi: 10.1002/2016JD024769.

Cohen J.L., Furtado J.C., Barlow M.A., Alexeev V.A. \& Cherry J.E. 2012a. Arctic warming, increasing snow cover and widespread boreal winter cooling. Environmental Research Letters 7, article no. 014007, doi: 10.1088/1748-9326/ 7/1/014007. 
Cohen J.L., Furtado J.C., Barlow M., Alexeev V.A. \& Cherry J.E. 2012b. Asymmetric seasonal temperature trends. Geophysical Research Letters 39, L04705, doi: 10.1029/2011GL050582.

Cohen J.L., Screen J.A., Furtado J.C., Barlow M., Whittleston D., Coumou D., Francis J., Dethloff K., Entekhabi D., Overland J. \& Jones J. 2014. Recent Arctic amplification and extreme mid-latitude weather. Nature Geoscience 7, 627-637, doi: 10.1038/ngeo2234.

Czaja A. \& Frankignoul C. 2002. Observed impact of Atlantic SST anomalies on the North Atlantic Oscillation. Journal of Climate 15, 606-623, doi: 10.1175/1520-0442(2002)015<0606:OIOASA>2.0.CO;2.

Estrada F., Perron P. \& Martínez-López B. 2013. Statistically derived contributions of diverse human influences to twentieth-century temperature changes. Nature Geoscience 6, 1050-1055, doi: 10.1038/ngeo1999.

Francis J.A. \& Vavrus S.J. 2012. Evidence linking Arctic amplification to extreme weather in mid-latitudes. Geophysical Research Letters 39, L06801, doi: 10.1029/2012GL051000.

Fuller W.A. 1976. Introduction to statistical time series. New York: John Wiley and Sons.

García-Serrano J., Frankignoul C., Gastineau G. \& Cámara A. 2015. On the predictability of the winter Euro-Atlantic climate: lagged influence of autumn Arctic sea ice. Journal of Climate 28, 5195-5216, doi: 10.1175/JCLI-D-14-00472.1.

Hansen J., Ruedy R., Sato M. \& Lo K. 2010. Global surface temperature change. Reviews of Geophysics 48, RG4004, doi: 10.1029/2010RG000345.

Honda M., Inoue J. \& Yamane S. 2009, Influence of low Arctic sea-ice minima on anomalously cold Eurasian winters. Geophysical Research Letters 36, L08707, doi: 10.1029/2008GL037079.

Inoue J., Hori M.E. \& Takaya K. 2012. The role of Barents Sea ice in the wintertime cyclone track and emergence of a warm-Arctic cold-Siberian anomaly. Journal of Climate 25, 2561-2568, doi: 10.1175/JCLI-D-11-00449.1.

Jaiser R., Dethloff K. \& Handorf D. 2013. Stratospheric response to Arctic sea ice retreat and associated planetary wave propagation changes. Tellus Series A 65, article no. 19375, doi: 10.3402/tellusa.v65i0.19375.

Kaufmann R.K., Kauppi H., Mann M.L. \& Stock J.H. 2011. Reconciling anthropogenic climate change with observed temperature 1998-2008. Proceedings of the National Academy of Sciences of the United States of America 108, 11790-11793, doi: 10.1073/pnas.1102467108.

Kim D. \& Perron P. 2009. Assessing the relative power of structural break tests using a framework based on the approximate Bahadur slope. Journal of Econometrics 149, 26-51, doi: 10.1016/j.jeconom.2008.10.010.

Kim K.Y. \& Son S.W. 2016. Physical characteristics of Eurasian winter temperature variability. Environmental Research Letters 11, article no. 044009, doi: 10.1088/1748-9326/11/4/044009.

Kim B.M., Son S.W., Min S.K., Jeong J.H., Kim S.J., Zhang X., Shim T. \& Yoon J.H. 2014. Weakening of the stratospheric polar vortex by Arctic sea-ice loss. Nature Communications 5, article no. 4646, doi: 10.1038/ncomms5646.
King M.P., Hell M. \& Keenlyside N. 2016. Investigation of the atmospheric mechanisms related to the autumn sea ice and winter circulation link in the Northern Hemisphere. Climate Dynamics 46, 1185-1195, doi: 10.1007/ s00382-015-2639-5.

Kosaka Y. \& Xie S.P. 2013. Recent global-warming hiatus tied to equatorial Pacific surface cooling. Nature 501, 403-407, doi: 10.1038/nature 12534 .

Kug J.S., Jeong J.H., Jang Y.S., Kim B.M., Folland C.K., Min S.K. \& Son S.W. 2015. Two distinct influences of Arctic warming on cold winters over North America and East Asia. Nature Geoscience 8, 759-763, doi: 10.1038/ NGEO2517.

Li C., Stevens B. \& Marotzke J. 2015. Eurasian winter cooling in the warming hiatus of 1998-2012. Geophysical Research Letters 42, 8131-8139, doi: 10.1002/2015GL065327.

Liu J., Curry J.A., Wang H., Song M. \& Horton R.M. 2012. Impact of declining Arctic sea ice on winter snowfall. Proceedings of the National Academy of Sciences of the United States of America 109, 4074-4079, doi: 10.1073/ pnas.1114910109.

McCusker K.E., Fyfe J.C. \& Sigmond M. 2016. Twenty-five winters of unexpected Eurasian cooling unlikely due to Arctic sea-ice loss. Nature Geoscience 9, 838-842, doi: 10.1038/ngeo2820.

Meehl G.A., Arblaster J.M., Fasullo J.T., Hu A. \& Trenberth K.E. 2011 . Model-based evidence of deep-ocean heat uptake during surface-temperature hiatus periods. Nature Climate Change 1, 360-364, doi: 10.1038/ NCLIMATE 1229.

Meehl G.A., Hu A., Arblaster J.M., Fasullo J. \& Trenberth K.E. 2013. Externally forced and internally generated decadal climate variability associated with the interdecadal Pacific oscillation. Journal of Climate 26, 7298-7310, doi: 10.1175/JCLI-D-12-00548.1.

Meehl G.A., Teng H. \& Arblaster J.M. 2014. Climate model simulations of the observed early-2000s hiatus of global warming. Nature Climate Change 4, 898-902, doi: 10.1038/ nclimate2357.

Mori M., Kosaka Y., Watanabe M., Nakamura H. \& Kimoto M. 2019. A reconciled estimate of the influence of Arctic sea-ice loss on recent Eurasian cooling. Nature Climate Change 9, 123-129, doi: 10.1038/s41558-018-0379-3.

Mori M., Watanabe M., Shiogama H., Inoue J. \& Kimoto M. 2014. Robust Arctic sea-ice influence on the frequent Eurasian cold winters in past decades. Nature Geoscience 7, 869-873, doi: 10.1038/ngeo2277.

Nakamura T., Yamazaki K., Iwamoto K., Honda M., Miyoshi Y., Ogawa Y., Tomikawa Y. \& Ukita J. 2016. The stratospheric pathway for Arctic impacts on midlatitude climate. Geophysical Research Letters 43, 3494-3501, doi: 10.1002/2016GL068330.

Ogawa F., Keenlyside N., Gao Y., Koenigk T., Yang S., Suo L., Wang T., Gastineau G., Nakamura T., Cheung H.N., Omrani N.-E., Ukita J. \& Semenov V. 2018. Evaluating impacts of recent Arctic sea ice loss on the Northern Hemisphere winter climate change. Geophysical Research Letters 45, 3255-3263, doi: 10.1002/2017GL076502. 
Outten S.D. \& Esau I. 2012. A link between Arctic sea ice and recent cooling trends over Eurasia. Climatic Change 110, 1069-1075, doi: 10.1007/s10584-011-0334-z.

Overland J., Francis J.A., Hall R., Hanna E., Kim S.J. \& Vihma T. 2015. The melting Arctic and midlatitude weather patterns: are they connected? Journal of Climate 28, 7917-7932, doi: 10.1175/JCLI-D-14-00822.1.

Peings Y. \& Magnusdottir G. 2014. Response of the wintertime Northern Hemisphere atmospheric circulation to current and projected Arctic sea ice decline: a numerical study with CAM5. Journal of Climate 27, 244-264, doi: 10.1175/ JCLI-D-13-00272.1.

Perron P. \& Yabu T. 2009. Testing for shifts in trend with an integrated or stationary noise component. Journal of Business O Economic Statistics 27, 369-396, doi: 10.1198/ jbes.2009.07268.

Petoukhov V. \& Semenov V.A. 2010. A link between reduced Barents-Kara sea ice and cold winter extremes over northern continents. Journal of Geophysical Research-Atmospheres 115, article no. D21111, doi: 10.1029/2009JD013568.

Screen J.A. 2017. Simulated atmospheric response to regional and pan-Arctic sea ice loss. Journal of Climate 30, 3945-3962, doi: 10.1175/JCLI-D-16-0197.1.

Screen J.A., Deser C., Smith D.M., Zhang X., Blackport R., Kushner P.J., Oudar T., McCusker K.E. \& Sun L. 2018. Consistency and discrepancy in the atmospheric response to Arctic sea-ice loss across climate models. Nature Geoscience 11, 155-163, doi: 10.1038/s41561-018-0059-y.

Sun L., Deser C. \& Tomas R.A. 2015. Mechanisms of stratospheric and tropospheric circulation response to projected Arctic sea ice loss. Journal of Climate 28, 7824-7845, doi: 10.1175/JCLI-D-15-0169.1.

Sun L., Perlwitz J. \& Hoerling M. 2016. What caused the recent "warm Arctic, cold continents" trend pattern in winter temperatures? Geophysical Research Letters 43, 5345-5352, doi: 10.1002/2016GL069024.

Tang Q., Zhang X., Yang X. \& Francis J.A. 2013. Cold winter extremes in northern continents linked to Arctic sea ice loss. Environmental Research Letters 8, article no. 014036 , doi: 10.1088/1748-9326/8/1/014036.

Thompson D.W., Wallace J.M. \& Hegerl G.C. 2000. Annular modes in the extratropical circulation. Part II: trends. Journal of Climate 13, 1018-1036, doi: 10.1175/1520-0442(2000)013<1018:AMITEC>2.0.CO;2.

Wallace J.M., Smith C. \& Bretherton C.S. 1992. Singular value decomposition of wintertime sea surface temperature and 500-mb height anomalies. Journal of Climate 5, 561-576, doi: 10.1175/1520-0442(1992)005<0561:SVDO WS $>2.0$.CO;2.

Walsh J.E. 2014. Intensified warming of the Arctic: causes and impacts on middle latitudes. Global and Planetary Change 117, 52-63, doi: 10.1016/j.gloplacha.2014.03.003.

Wu Y. \& Smith K.L. 2016. Response of Northern Hemisphere midlatitude circulation to Arctic amplification in a simple atmospheric general circulation model. Journal of Climate 29, 2041-2058, doi: 10.1175/JCLI-D-15-0602.1.

Xu X., Li F., He S. \& Wang H. 2018. Subseasonal reversal of East Asian surface temperature variability in winter 2014/15. Advanced in Atmospheric Sciences 35, 737-752, doi: 10.1007/s00376-017-7059-5.

Zhang P., Wu Y. \& Smith K.L. 2018. Prolonged effect of the stratospheric pathway in linking Barents-Kara sea ice variability to the midlatitude circulation in a simplified model. Climate Dynamics 50, 527-539, doi: 10.1007/s00382-017-3624-y.

Zhang X., Sorteberg A., Zhang J., Gerdes R. \& Comiso J.C. 2008. Recent radical shifts of atmospheric circulations and rapid changes in Arctic climate system. Geophysical Research Letters 35, L22701, doi: 10.1029/2008GL035607. 